Revista Brasileira de Agricultura Irrigada v.12, nº.6, p. 3012 - 3020, 2018

ISSN 1982-7679 (On-line)

Fortaleza, CE, INOVAGRI - http://www.inovagri.org.br

DOI: $10.7127 /$ rbai.v12n600886

Protocolo 886.18 - 26/02/2018 Aprovado em 13/01/2019

\title{
PRODUÇÃO DE MUDAS DE MORINGA (Moringa oleífera) SOB IRRIGAÇÃO COM ÁGUA SALINA E SUBSTRATOS
}

Jackson Silva Nóbrega ${ }^{1}$, Tássio Almeida Souza ${ }^{2}$, Lauter Silva Souto ${ }^{3}$, Joama Alves De Sousa $^{2}$, Francisco Romário Andrade Figueiredo ${ }^{4}$, Francisco Vanies da Silva Sá ${ }^{5 *}$

\section{RESUMO}

A moringa é uma espécie com alta capacidade de adaptar-se a condições adversas, possuindo um elevado potencial de exploração. Com isso, objetivou-se avaliar o crescimento inicial da moringa submetidas a diferentes níveis salinos em diferentes substratos. $\mathrm{O}$ experimento foi realizado em ambiente protegido, utilizando $\mathrm{o}$ delineamento em blocos casualizados, em um fatorial $2 \times 4$, onde foram aplicados dois níveis de salinidade $\left(\mathrm{NS}_{1}=0,3\right.$ e NS $\left.2=3,3 \mathrm{dSm}^{-1}\right)$ e quatro substratos $\left(\mathrm{SUB}_{1}=\right.$ Solo + esterco bovino curtido na proporção 9:1; $\mathrm{SUB}_{2}=\mathrm{SUB}_{1}+25 \mathrm{mg} \mathrm{dm}^{-3} \mathrm{de} \mathrm{N} ; \mathrm{SUB}_{3}=\mathrm{SUB} 1$ $+50 \mathrm{mg} \mathrm{dm}^{-3}$ de $\mathrm{N}$ e SUB $4=\mathrm{SUB}_{1}+100 \mathrm{mg} \mathrm{dm}^{-3} \mathrm{de} \mathrm{N}$ ), com quatro repetições e quatro plantas por repetição. As plantas foram germinadas em recipientes com capacidade de 5 $\mathrm{dm}^{3}$, aonde foram conduzidas por 90 dias após a semeadura. Nesse período as plantas foram avaliadas quanto ao crescimento e acúmulo de fitomassa. $\mathrm{O}$ aumento da salinidade da água de irrigação de 0,3 para $3,3 \mathrm{dS} \mathrm{m}^{-1}$ reduz o crescimento e o acúmulo de massa seca das mudas de moringa. O substrato contendo solo e esterco bovino na proporção 9:1 é adequado para produção de mudas de moringa na ausência de estresse salino. A adição de 25 e $50 \mathrm{mg} \mathrm{dm}^{-3}$ de $\mathrm{N}$ ao substrato composto por solo e esterco bovino na proporção 9:1 atenuou o estresse salino sobre as plantas de moringa, sendo adequado para produção de mudas de espécies sobre condições de estresse salino.

Palavras-chave: Moringa oleífera Lam., crescimento inicial, adubação nitrogenada, estresse salino.

\footnotetext{
1 Eng. Agrônomo, Mestrando em Agronomia, Universidade Federal da Paraíba, Areia-PB. E-mail: jacksonnobrega@hotmail.com

${ }^{2}$ Eng. Agrônomo(a), Universidade Federal de Campina Grande, Campus Pombal, Pombal-PB. E-mail: almeidatassio@gmail.com; joama_asousa@hotmail.com

${ }^{3}$ Eng. Agrônomo, Doutor em Agronomia, Professor, Universidade Federal de Campina Grande, Campus Pombal, Pombal-PB. E-mail: lauter@ccta.ufcg.edu.br

${ }^{4}$ Tecnólogo em Agroecologia, Mestrando em Agronomia, Universidade Federal da Paraíba, Areia-PB. Email: romarioagroecologia@yahoo.com.br

5 Eng. Agrônomo, Doutor em Engenharia Agrícola, Bolsista do Programa Nacional de Pós-Doutorado, Universidade Federal Rural do Semi-Árido, Campus Mossoró, Mossoró-RN. E-mail: vanies_agronomia@hotmail.com

*Autor Correspondente.
} 


\title{
MORINGA SEEDLINGS PRODUCTION (Moringa oleifera) UNDER IRRIGATION WITH SALINE WATER AND SUBSTRATES
}

\begin{abstract}
Moringa is a species with high capacity to adapt to adverse conditions, possessing a high exploitation potential. The objective of this study was to evaluate the initial growth of the moringa submitted to different saline levels in different substrates. The experiment was carried out in a protected environment using a randomized block design in a $2 \times 4$ factorial, where two salinity levels $\left(\mathrm{NS}_{1}=0.3\right.$ and $\left.\mathrm{NS}_{2}=3.3 \mathrm{dSm}^{-1}\right)$ and four substrates $\left(\mathrm{SUB}_{1}=\right.$ Soil + bovine manure tanned in the ratio 9: $1 ;, \mathrm{SUB}_{2}=\mathrm{SUB}_{1}+25 \mathrm{mg} \mathrm{dm}{ }^{-3}$ of $\mathrm{N}, \mathrm{SUB}_{3}=\mathrm{SUB}_{1}+50 \mathrm{mg} \mathrm{dm}^{-3}$ of $\mathrm{N}$ and $\mathrm{SUB}_{4}=\mathrm{SUB}_{1}+100 \mathrm{mg} \mathrm{dm}^{-3}$ of $\mathrm{N}$ ), with four replicates and four plants per replicate. The plants were germinated in containers with a capacity of $5 \mathrm{dm}^{3}$, where they were conducted for 90 days after sowing. During this period the plants were evaluated for the growth and accumulation of phytomass. Increasing the salinity of irrigation water from 0.3 to $3.3 \mathrm{dS} \mathrm{m}^{-1}$ reduces growth and dry mass accumulation of moringa seedlings. The substrate containing soil and cattle manure in the ratio 9: 1 is suitable for production of moringa seedlings in the absence of saline stress. The addition of 25 and $50 \mathrm{mg} \mathrm{dm}^{-3}$ of $\mathrm{N}$ to the substrate composed of soil and cattle manure in the ratio 9: 1 attenuated the saline stress on the moringa plants, being suitable for production of species seedlings under conditions of salt stress.
\end{abstract}

Palavras-chave: Moringa oleifera Lam., Initial growth, nitrogen fertilization, saline stress.

\section{INTRODUÇÃO}

A moringa (Moringa oleífera Lam.) é uma espécie de porte arbóreo e perene, pertencente à família Moringaceae, sendo originária do Nordeste indiano, apresenta grande capacidade de adaptação a diversas condições edafoclimáticas, sendo cultivada tanto de forma irrigada como em sequeiro (SILVA et al., 2011). Esta espécie possui potencial de exploração para diversas finalidades, tais como: alimentação humana e animal, produção de biodiesel, uso industrial e medicinal. De acordo com Gualberto et al. (2014), as suas folhas apresentam grande valor nutricional, podendo ser utilizada na alimentação humana e animal e também considerada como fonte constante de néctar, principalmente nas regiões coberta pela a Caatinga, a qual se caracteriza pela sazonalidade dos recursos hídricos.

A região Nordeste do Brasil em especial, caracteriza-se por possuir áreas semiáridas, as quais manejadas de maneira inadequada acabam sofrendo degradação química, física e biológica. A salinização dos solos vem ao longo dos anos, sendo um dos principais problemas enfrentado nas áreas agrícolas do nordeste brasileiro, esse processo é típico de regiões áridas e semiáridas, o qual é consequência de uma má distribuição das chuvas e principalmente exploração agrícola inadequada (SÁ et al., 2013; PEDROTTI et al., 2015).

Em solos salinos ocorre à redução na disponibilidade de água, pois o acúmulo de sais provoca uma queda no potencial total da solução, isso devido ao baixo potencial osmótico e consequentemente causando estresse para as plantas (DUARTE et al., 2015). As culturas de forma geral reagem de formas distintas quanto a níveis de salinidade, algumas são mais tolerantes (halófitas) do que outras (glicófitas) e podem extrair água com mais facilidade (DIAS; BLANCO, 2010).

Os efeitos da salinidade sobre as plantas ocorrem principalmente de duas formas, a primeira é o efeito osmótico, onde o aumento da salinidade reduz o potencial osmótico do solo restringindo absorção de água pela planta, e o efeito iônico, a qual ocorre de forma mais lenta e provoca toxicidade por íons específicos que estão em grande concentração nos solos (MUNS; TESTER, 2008). Sabendo que o aumento nos teores de sais 
solúveis ocasiona uma queda no potencial osmótico da solução do solo, trazendo como efeitos as culturas, dificuldade na absorção de água, deficiência nutricional e consequentemente redução no desenvolvimento e produção, torna-se necessário o fornecimento nutricional de forma satisfatória para que possa maximizar a produção mesmo em condições salinas (MENEZES JUNIOR et al., 2010; BEZERRA et al., 2014; SÁ et al., 2018).

De acordo com Oliveira et al. (2014) e Sá et al. (2017), o uso de forma correta dos adubos ricos em nitrogênio pode ser uma das alternativas para diminuir os efeitos da salinidade sobre 0 crescimento e desenvolvimentos das plantas, isso em virtude desse nutriente desempenhar função estrutural e participar de vários compostos orgânicos, assim, o sulfato de amônio, um fertilizante nitrogenado, surge como uma das fontes a serem estudas.

Com isso, objetivou-se avaliar o crescimento inicial da moringa submetidas a diferentes níveis salinos em diferentes substratos.

\section{MATERIAL E METÓDOS}

A pesquisa foi realizada em ambiente protegido do Centro de Ciências e Tecnologia Agroalimentar da Universidade Federal de Campina Grande, Campus de Pombal-PB. Este município é localizado no sertão paraibano, apresentando as coordenadas de $06^{\circ} 46^{\prime} 13^{\prime \prime}$ S e $37^{\circ} 48^{\prime} 06^{\prime}$ 'W, e altitude em torno de $242 \mathrm{~m}$. O clima predominante, com base na classificação de Köppen, é do tipo Bsh (semiárido) quente e seco, possuindo pluviosidade em torno de $700 \mathrm{~mm}$ por ano, com chuvas torrenciais ao longo do período chuvoso.

$\mathrm{O}$ experimento foi conduzido em delineamento de blocos casualizados, em esquema fatorial $2 \times 4$, onde foram aplicados dois níveis de salinidade (NS1 $=0,3$ e NS2 $=3,3 \mathrm{dSm}^{-1}$ ), e quatro substratos $\left(\mathrm{SUB}_{1}=\right.$ Solo + esterco bovino curtido na proporção 9:1; $\mathrm{SUB}_{2}=\mathrm{SUB}_{1}+25 \mathrm{mg} \mathrm{dm}^{-3} \mathrm{de}$ $\mathrm{N} ; \mathrm{SUB}_{3}=\mathrm{SUB} 1+50 \mathrm{mg} \mathrm{dm}{ }^{-3}$ de $\mathrm{N}$ e SUB $4=$ $\mathrm{SUB}_{1}+100 \mathrm{mg} \mathrm{dm}^{-3} \mathrm{de} \mathrm{N}$ ), com quatro repetições e quatro plantas por repetição.

Para instalação do experimento foi utilizado vasos com capacidade de $5 \mathrm{dm}^{-3}$, sendo os mesmos preenchidos com solo e esterco bovino curtido a proporção de $10 \% \mathrm{v} / \mathrm{v}$ (Tabelas 1 e 2). O solo utilizado no experimento é classificado como Neossolo Flúvico Eutrófico (SANTOS et al., 2013), apresentou, nos primeiros $20 \mathrm{~cm}$ de profundidade, 661, 213 e $126 \mathrm{~g} \mathrm{~kg}^{-1}$ de areia, silte, argila; densidade do solo e de partículas, 1,51 e $2,76 \mathrm{~g} \mathrm{~cm}^{-3}$, respectivamente, com porosidade total de $0,45 \mathrm{~m}^{3} \mathrm{~m}^{-3}$. Os valores da umidade na capacidade de campo, ponto de murchamento permanente e água disponível foram 23,$52 ; 7,35$ e $16,17 \%$, respectivamente. Quanto à caracterização química, do solo na mesma profundidade e da esterco bovino foi determinada conforme as metodologias de Embrapa (2011) (Tabelas 1 e 2).

Tabela 1. Características químicas dos componentes do solo usados no experimento.

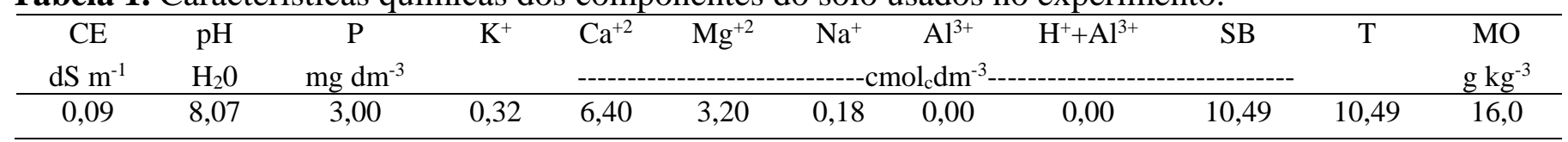

$\overline{\mathrm{SB}}=$ soma de bases; $\mathrm{CE}=$ condutividade elétrica; $\mathrm{T}=$ capacidade de troca de cátions total; $\mathrm{M} . \mathrm{O}=$ matéria orgânica; $\mathrm{A}=\mathrm{Solo} ; \mathrm{B}=$ substrato comercial.

Tabela 2. Caracterização química do esterco bovino utilizado como fonte de matéria orgânica.

\begin{tabular}{ccccccccccccc}
\hline $\mathrm{N}$ & $\mathrm{P}$ & $\mathrm{K}$ & $\mathrm{Ca}$ & $\mathrm{Mg}$ & $\mathrm{Na}$ & $\mathrm{Zn}$ & $\mathrm{Cu}$ & $\mathrm{Fe}$ & $\mathrm{Mn}$ & $\mathrm{CO}$ & $\mathrm{CTC}$ & $\mathrm{C} / \mathrm{N}$ \\
\hline & $\ldots \ldots \ldots \ldots \ldots . \mathrm{g} \mathrm{kg}^{-1} \ldots \ldots \ldots \ldots \ldots \ldots \ldots \ldots$ & & & $\ldots \ldots \ldots . \mathrm{mg} \mathrm{kg}^{-1} \ldots \ldots \ldots \ldots$ & & $\%$ & $\mathrm{cmolc} \mathrm{dm}-3$ & $-\ldots \ldots \ldots$ \\
\hline 14,85 & 3,25 & 1,16 & 16,11 & 3,07 & 0,66 & 65 & 15 & 3,775 & 121 & 10,70 & 34,24 & $7: 1$ \\
\hline
\end{tabular}

$\mathrm{CO}=$ Carbono orgânico; $\mathrm{CTC}=$ Capacidade de troca de cátions.

As sementes utilizadas foram coletadas de plantas matrizes presentes na própria estrutura do Campus, sendo realizada a seleção das plantas sadias sem a ocorrência de doenças e ataque de pragas. Após a coleta das vagens foram retiradas as sementes e postas para secar por sete dias a 
temperatura ambiente. A semeadura foi realizada a $1 \mathrm{~cm}$ de profundida e na posição transversal, sendo as mesmas previamente desinfestadas com solução de hipoclorito a $2 \%$ durante 5 minutos e lavadas em água corrente. Posteriormente a semeadura realizou-se o desbaste do excesso de plantas, deixando apenas uma planta por vaso, sendo realizados 15 dias após a semeadura.

As irrigações eram diárias, sendo estabelecido o volume de água em função da evapotranspiração média da testemunha $\left(0,3 \mathrm{dS} \mathrm{m}^{-}\right.$ ${ }^{1}$ ), calculando-se o volume de água a ser aplicada por meio da equação 1:

$$
V a=P c c-\frac{P a}{n}
$$

Em que: $\mathrm{Va}=$ volume aplicado; $\mathrm{Pcc}=$ peso do recipiente na máxima capacidade de retenção de água; $\mathrm{Pa}=$ peso atual; $\mathrm{n}=$ número de recipientes.

As soluções salinas foram preparadas utilizando o cloreto de sódio $(\mathrm{NaCl})$ sendo pesadas as proporções de sais em balança analítica de precisão a $0,1 \mathrm{~g}$, e em seguida sendo diluídas em tambores com capacidade de $200 \mathrm{~L}$, realizando as aferições com condutivímetro portátil a cada dois dias, com regulação dos níveis caso fosse necessário, sendo as soluções aplicada a partir do dia em que realizou-se a semeadura.

A aplicação das doses de sulfato de amônio foi realizada após o estabelecimento da emergência, sendo as mesmas pesadas em balança analítica de precisão a $0,1 \mathrm{~g}$, e em seguida diluindoas em água aplicando-se $100 \mathrm{ml}$ da solução por vaso. Durante a condução do experimento foram realizados a eliminação de plantas daninhas e a escarificação da crosta superficial do solo para melhorar a infiltração da água.

Aos 45 dias após a semeadura s plantas de moringa foram avaliadas quanto: o número de

folhas, realizado a partir da contagem das folhas, considerando as folhas completamente formadas; a altura de plantas, obtida a partir da retirada da medida da parte aérea das plantas, considerando-se a parte acima do colo da planta até o ápice. A mesma foi realizada com o auxílio de régua graduada. Os resultados foram expressos em cm; o diâmetro do caule obtido com o auxílio de um parquímetro digital, sendo os resultados expressos em mm; a massa seca da parte aérea, da raiz e total, para obtenção destas a parte aérea e as raízes foram coletada e acondicionadas em sacos de papel Kraft e postas para secar em estufa de circulação de ar forçada e mantidas em estufa a $65^{\circ} \mathrm{C}$, até atingir peso constante (AGUIAR et al., 2014). Após atingirem o peso constante, as partes foram pesadas em balança analítica de precisão de 0,01g. A massa seca total foi obtida a partir do somatório dos valores da parte aérea e da raiz. Os resultados foram expressos em $g$ planta ${ }^{-1}$.

Os dados foram analisados por meio de análise de variância, em caso de significância $(\mathrm{p}<$ $0,05)$ utilizou-se o teste t de Student ao nível de 5\% de probabilidade para o fator salinidade da água de irrigação e teste de Tukey ao nível de $5 \%$ de probabilidade para o fator substratos. Para as análises foi utilizado o software SISVAR ${ }^{\circledR}$, versão 5.6. (FERREIRA, 2011).

\section{RESULTADOS E DISCUSSÃO}

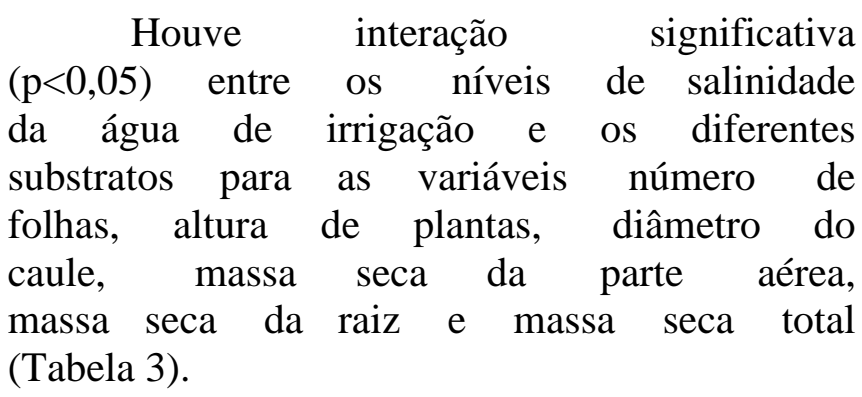

Tabela 3. Resumo de significância do teste 'F' para as variáveis número de folhas (NF), altura de plantas (ALT), diâmetro do caule (DC), massa seca da parte aérea (MSP), massa seca da raiz (MSR) e massa seca total (MST) de mudas de moringa submetidas a diferentes níveis salinos e substratos aos 45 dias após a semeadura.

\begin{tabular}{cccccccc}
\hline \multirow{2}{*}{ Fontes de variação } & \multirow{2}{*}{ GL } & \multicolumn{7}{c}{ Variáveis analisadas } \\
\cline { 3 - 8 } & 2 & NF & ALT & DC & MSP & MSR & MST \\
\hline Bloco & 1 & $*$ & $*$ & NS & NS & NS & NS \\
Salinidade (NS) & 3 & NS & $*$ & $*$ & $*$ & $*$ & $*$ \\
Substratos (SUB) & 3 & $*$ & $*$ & $*$ & $*$ & $*$ & $*$ \\
NS x SUB & 14 & 0,56 & 4,70 & 0,0001 & 0,0003 & 0,0002 & 0,0006 \\
Erro & & 6.71 & 22,29 & 0,11 & 0,57 & 0,15 & 0,71 \\
\hline Média & & & & & & &
\end{tabular}




\begin{tabular}{ccrrrrr}
\hline Coeficiente de variação (\%) & 11,21 & 9,73 & 11,41 & 3,39 & 11,12 & 3,64 \\
\hline${ }_{\text {ns }}$ não significativo; ${ }^{*}$ significativo a 5\% de probabilidade pelo teste F. & & & & &
\end{tabular}

Para o número de folhas das plantas de moringa foi observado reduções em aumento da salinidade da água de irrigação em todos dos substratos estudados (Tabela 4). Em condições de baixa salinidade não foi observado diferença significativa entre os substratos, no entanto, sob condições de salinidade o número de folhas das plantas de moringa foi maior nos substratos 2 (Solo + esterco bovino curtido na proporção 9:1 $+25 \mathrm{mg} \mathrm{dm}^{-3}$ de N) e 3 (Solo + esterco bovino curtido na proporção $9: 1+50 \mathrm{mg} \mathrm{dm}^{-3}$ de $\mathrm{N}$ ) (Tabela 4). Com isso, podemos denotar que adição de nitrogênio junto ao substrato com esterco bovino reduz os efeitos do estresse salino sobre a emissão das folhas de moringa, provavelmente sobre condições de salinidade a velocidade da mineralização do adubo orgânico não supre as necessidades de nitrogênio das plantas de moringa.
A redução do número de folhas das plantas de moringa ocorre em virtude dos efeitos osmóticos, e especificamente os efeitos de íons específicos, prejudicando o metabolismo da planta, uma vez que a presença desses íons afetam a capacidade de absorção, transporte e utilização a partir do acúmulo nos tecidos vegetais (NOBRE et al., 2010). De acordo com Nobre et al. (2013), as plantas quando cultivadas sobre estresse salino, sofrem grandes distúrbio em seu crescimento, desenvolvimento e produção, principalmente injúrias promovidas nas folhas. A redução do número de folhas em função da salinidade está relacionado ao fato delas serem responsáveis pelo processo de transpiração, sendo assim, essa redução na emissão poder ser uma artificio adotado pelas plantas para reduzir a perda de água pela transpiração (OLIVEIRA et al., 2013; SÁ et al., 2017).

Tabela 4. Teste de médias para as variáveis de número de folhas (NF), altura de plantas (ALT), diâmetro do caule (DC), massa seca da parte aérea (MSP), massa seca da raiz (MSR) e massa seca total (MST) de mudas de moringa submetida a diferentes níveis salinos e substratos aos 45 dias após a semeadura.

\begin{tabular}{ccccccc}
\hline & \multicolumn{7}{c}{ Salinidade da água de irrigação $\left(\mathrm{dS} \mathrm{m}{ }^{-1}\right)$} \\
\cline { 2 - 7 } Substratos & 0,3 & 3,3 & 0,3 & 3,3 & 0,3 & 3,3 \\
\cline { 2 - 7 } & \multicolumn{2}{c}{$\mathrm{NF}$} & \multicolumn{2}{c}{ ALT $(\mathrm{cm})$} & \multicolumn{2}{c}{ DC $(\mathrm{mm})$} \\
\hline 1 & $8,00 \mathrm{Aa}$ & $5,67 \mathrm{Bab}$ & $30,33 \mathrm{Aa}$ & $16,00 \mathrm{Ba}$ & $0,14 \mathrm{Aa}$ & $0,08 \mathrm{Bb}$ \\
3 & $7,67 \mathrm{Aa}$ & $6,33 \mathrm{Ba}$ & $28,67 \mathrm{Aa}$ & $19,00 \mathrm{Ba}$ & $0,13 \mathrm{Aa}$ & $0,08 \mathrm{Bb}$ \\
4 & $8,00 \mathrm{Aa}$ & $6,00 \mathrm{Ba}$ & $32,00 \mathrm{Aa}$ & $16,00 \mathrm{Ba}$ & $0,14 \mathrm{Aa}$ & $0,11 \mathrm{Ba}$ \\
\hline Substratos (SUB) & $8,00 \mathrm{Aa}$ & $4,00 \mathrm{Bb}$ & $27,33 \mathrm{Aa}$ & $9,00 \mathrm{Bb}$ & $0,12 \mathrm{Aa}$ & $0,05 \mathrm{Bc}$ \\
\hline 1 & \multicolumn{2}{c}{$\mathrm{MSP}\left(\mathrm{g} \mathrm{planta}^{-1}\right)$} & \multicolumn{2}{c}{$\mathrm{MSR}\left(\mathrm{g} \mathrm{planta}^{-1}\right)$} & \multicolumn{2}{c}{$\mathrm{MST}\left(\mathrm{g} \mathrm{planta}^{-1}\right)$} \\
\hline 2 & $0,86 \mathrm{Ac}$ & $0,32 \mathrm{Ba}$ & $0,21 \mathrm{Ab}$ & $0,07 \mathrm{~B} \mathrm{a}$ & $1,06 \mathrm{Ab}$ & $0,39 \mathrm{Bab}$ \\
3 & $0,79 \mathrm{Ab}$ & $0,35 \mathrm{Ba}$ & $0,26 \mathrm{Aa}$ & $0,06 \mathrm{Ba}$ & $1,05 \mathrm{Ab}$ & $0,41 \mathrm{Ba}$ \\
4 & $0,98 \mathrm{Aa}$ & $0,36 \mathrm{Ba}$ & $0,24 \mathrm{Aab}$ & $0,07 \mathrm{Ba}$ & $1,22 \mathrm{Aa}$ & $0,40 \mathrm{Ba}$ \\
& $0,70 \mathrm{Ad}$ & $0,32 \mathrm{Ba}$ & $0,16 \mathrm{Ac}$ & $0,09 \mathrm{Ba}$ & $0,86 \mathrm{Ac}$ & $0,33 \mathrm{Bb}$ \\
\hline
\end{tabular}

$\mathrm{SUB}_{1}=$ Solo + esterco bovino curtido na proporção 9:1; $\mathrm{SUB}_{2}=\mathrm{SUB}_{1}+25 \mathrm{mg} \mathrm{dm}^{-3} \mathrm{de} \mathrm{N} ; \mathrm{SUB}_{3}=\mathrm{SUB} 1+50 \mathrm{mg} \mathrm{dm}^{-3} \mathrm{de} \mathrm{Ne}$ $\mathrm{SUB}_{4}=\mathrm{SUB}_{1}+100 \mathrm{mg} \mathrm{dm}^{-3}$ de $\mathrm{N}$. Letras minúsculas iguais na coluna não diferem perante o teste de Tukey ao nível de $5 \%$ de probabilidade para os substratos. Letras maiúsculas iguais na linha não diferem perante o teste 't' de Student ao nível de 5\% de probabilidade para os níveis de salinidade.

Resultados semelhantes aos encontrados por Silva et al. (2011), em plantas de moringa que em função do aumento dos níveis salinos, constataram uma redução de 0,35 e 1,65 por planta, com 30 e 60 dias, respectivamente. Já Bezerra et al. (2013), em plantas de turco (Parkinsonia aculeata L.) constataram que com o aumento da salinidade ocorreu também um aumento linear na emissão do número de folhas.

A altura das plantas de moringa também foi reduzida pelo aumento da salinidade da água de irrigação de 0,3 para $3,3 \mathrm{dS} \mathrm{m}^{-1}$ independente do substrato estudados (Tabela 4). De acordo com Freire et al. (2010), esse efeito pode ser promovido pela diminuição da turgescência celular exercido 
pelo estresse salino, resultando em menor conteúdo de água nos tecidos, afetando a divisão e alongamento celular e, consequentemente, promovendo menor crescimento da planta. Resultados semelhantes aos observados por Oliveira et al. (2013), que constataram um elevado decréscimo na altura de plantas de moringa em razão do aumento da salinidade, chegando a atingir uma redução de $56,28 \%$ ao serem submetidas ao nível de $5 \mathrm{dSm}^{-1}$.

Quando submetidas a condições de alta salinidade a menor altura das plantas de moringa foi observado nas mudas do substrato 4 (Solo + esterco bovino curtido na proporção 9:1 + $100 \mathrm{mg}$ $\mathrm{dm}^{-3}$ de N), denotando que adição de $100 \mathrm{mg} \mathrm{dm}^{-3}$ de $\mathrm{N}$ foi excessiva para as plantas de moringa, promovendo intensificação dos efeitos do estresse salino. Este efeito pode ter sido promovido pela elevação da salinidade do solo em função dos sais contidos no fertilizante, resultando em menor capacidade da planta em absorver água e nutrientes para seu crescimento. De acordo com Leite et al. (2017), a adubação nitrogenada em excesso pode promover sérios problemas a planta, podendo resultar em perdas significativas de crescimento e produção.

Nobre et al. (2010), avaliando o efeito da salinidade e adubação nitrogenada com uréia e nitrato de potássio em girassol, observaram que a salinidade promoveu um decréscimo de 3,1\% na altura de plantas e não constataram efeito significativo da adubação nitrogenada. De forma contraditória, Campos et al. (2010) afirmou que independentemente do nível salino, a utilização do sulfato de amônio como suplementação de nitrogênio mantém o equilíbrio no desenvolvimento vegetativo das plantas de girassol.

Assim como observado para a altura e número de folhas o diâmetro do caule das plantas de moringa também foram reduzidos pelo aumento da salinidade da água de 0,3 para $3,3 \mathrm{dS} \mathrm{m}^{-1} \mathrm{em}$ todos os substratos estudados (Tabela 4). Com tudo, as mudas produzidas no substrato 3 (Solo + esterco bovino curtido na proporção 9:1 $+50 \mathrm{mg}$ $\mathrm{dm}^{-3}$ de N) obtiveram maiores diâmetros do caule em relação ao demais substratos, indicando influência positiva do acréscimo de $\mathrm{N}$ ao substrato (Tabela 4). Esse efeito atenuante se deve ao fato do nitrogênio atuar desempenhando funções importantes no metabolismo vegetal, uma vez que este nutriente é componente estrutural de algumas moléculas como a clorofila e os ácidos nucléicos, além de atuar como ativador de muitas enzimas responsáveis por processos metabólicos e bioquímicos da planta (LIMA et al., 2014).

$\mathrm{O}$ aporte de nutrientes em condições adequadas promove melhorias no crescimento e desenvolvimento da planta, no entanto, o fornecimento em excesso pode acarretar em sérios distúrbios fisiológicos, resultando em baixa capacidade de absorção de nutrientes e, consequentemente, desequilíbrio nutricional e efeitos fitotóxicos a planta (COSTA et al., 2012; SÁ et al., 2018).

Para a massa seca da parte aérea e das raízes, observou-se que a irrigação com alta salinidade reduziu o acúmulo de matéria seca independente dos substratos, haja vista que não houve diferença significativa entre substratos em condições de alta salinidade da água de irrigação (Tabela 4). De acordo com Azevedo et al. (2017) os sais solúveis, principalmente o cloro e o sódio quando em excesso no solo ou na água de irrigação provocam distúrbios fisiológicos, em especial nas culturas mais susceptíveis. Assim, os vegetais de modo geral quando submetidos a condições de estresse salino tendem a fechar as plantas devido a diminuição no potencial osmótico do solo, e como consequência ocorre uma baixa na taxa fotossintética, e consequentemente diminuição no acúmulo de biomassa (MUNNS; TESTER, 2008; NOBRE et al., 2010; SÁ et al., 2013). No entanto as mudas em condições de baixa salinidade sofreram reduções no acúmulo de fitomassa no substrato 4 , onde se tem o maior acréscimo de nitrogênio, esse fato indica que a combinação Solo + esterco bovino curtido na proporção 9:1 + $100 \mathrm{mg}$ $\mathrm{dm}^{-3}$ de $\mathrm{N}$ é inviável para a produção de mudas de moringa.

A massa seca total das mudas de moringa também foram reduzidas pelo aumento da salinidade da água de 0,3 para $3,3 \mathrm{dS} \mathrm{m}^{-1}$, em todos os substratos estudados, todavia as mudas produzidas nos substratos 2 (Solo + esterco bovino curtido na proporção $9: 1+25 \mathrm{mg} \mathrm{dm}^{-3}$ de N) e 3 (Solo + esterco bovino curtido na proporção 9:1 + $50 \mathrm{mg} \mathrm{dm}^{-3}$ de N) obtiveram os maiores acúmulos de matéria seca total (Tabela 4). O excesso de sais no solo provoca uma redução na disponibilidade de água para as plantas e isso faz com que as mesmas tendem a gastar mais energia para a absorção, tendo 
como consequência uma menor capacidade de acumular reservas (OLIVEIRA et al., 2015; SÁ et al., 2018). No entanto as plantas dos substratos $2 \mathrm{e}$ 3 que receberam acréscimo de nitrogênio no substrato apresentaram melhor desempenho, o que pode estar relacionado a mecanismos de ajustamento osmóticos, para reduzir os efeitos promovidos pelos íons contidos nos sais, ocorrendo modificações morfológicas ou fisiológica, como a redução da biomassa seca das plantas (TAIZ et al., 2017), induzidos pela disponibilidade adequada de $\mathrm{N}$ no substrato.

\section{CONCLUSÕES}

O aumento da salinidade da água de irrigação de 0,3 para $3,3 \mathrm{dS} \mathrm{m}^{-1}$ reduz o crescimento e o acúmulo de massa seca das mudas de moringa.

O substrato contendo solo e esterco bovino na proporção 9:1 é adequado para produção de mudas de moringa na ausência de estresse salino.

A adição de 25 e $50 \mathrm{mg} \mathrm{dm}^{-3}$ de $\mathrm{N}$ ao substrato composto por solo e esterco bovino na proporção 9:1 atenuou o estresse salino sobre as plantas de moringa, sendo adequado para produção de mudas de espécies sobre condições de estresse salino.

\section{REFERÊNCIAS}

AGUIAR, R. S.; YAMAMOTO, L. Y.; PRETI, E. A.; SOUZA, G. R. B.; SBRUSSI, C. A. G.; OLIVEIRA, E. A. P.; ASSIS, A. M.; ROBERTO, S. R.; NEVES, C. S. V. J. Extração de mucilagem e substratos no desenvolvimento de plântulas de maracujazeiro-amarelo. Semina: Ciências Agrárias, v. 35, n. 2, p. 605-612, 2014. https://doi.org/10.5433/1679-

0359.2014v35n2p605.

AZEVEDO, P. R. L; BEZERRA, D. E. L; SOUTO, F. M; BITU, S. G; PEREIRA JUNIOR, E. D. Efeito dos sais e da qualidade da água no solo e na planta. Revista de Agroecologia no Semiárido, v. 1, n. 1, p. 01-12, 2017.

BEZERRA, F. T. C.; ANDRADE, L. A.; CAVALCANTE, L. F.; PEREIRA, W. E.; BEZERRA, M. A. F. Emergência e crescimento inicial de plantas de Parkinsonia aculeata 1. (fabaceae) em substrato salino. Revista Árvore, v. 37, n. 4, p. 611-618, 2013. http://dx.doi.org/10.1590/S010067622013000400004.

BEZERRA. M. A. F.; PEREIRA, W. E.; BEZERRA, T. C.; FERREIRA, L. C.; MEDEIROS, S. A. S. Água salina e nitrogênio na emergência e biomassa de mudas de maracujazeiro amarelo. Revista Agropecuária Técnica, v. 35, n. 1, p. 150-160, 2014. https://doi.org/10.25066/agrotec.v35i1.19920.

CAMPOS. M. S.; OLIVEIRA, F. A.; OLIVEIRA, F. R. A.; SILVA, R. C. P.; CÂNDIDO, W. S. Efeito da salinidade e fontes de nitrogênio na matéria seca do girassol. Revista Verde de Agroecologia e Desenvolvimento Sustentável, v. 5, n. 3, p.165171, 2010.

COSTA, E.; FERREIRA, A. F. A. SILVA, P. N. L.; NARDELLI, E. M. V. Diferentes composições de substratos e ambientes protegidos na formação de mudas pé-franco de tamarindeiro. Revista Brasileira de Fruticultura, v. 34, n. 4, p. 11891198, 2012. http://dx.doi.org/10.1590/S010029452012000400028.

DIAS, N. S.; BLANCO, F. F. Efeitos dos sais no solo e na planta. In.: GHEYI, H. R.; DIAS, N. S.; LACERDA, C. F. Manejo da salinidade na agricultura: estudos básicos e aplicados. Fortaleza: INCTSal, cap. 9, 129-142, 2010.

DUARTE, S. N; SILVA, E. F. F; MIRANDA, J. H; MEDEIROS, J. F; COSTA, R. N. T; GHEYI, H. R. Fundamentos de Drenagem Agrícola. Fortaleza: Inctsal, 338 p. 2015.

EMBRAPA. Centro Nacional de Pesquisa de Solos. Manual de métodos de análise do solo. 3 ed. Rio de Janeiro, 2011, 230 p. (Embrapa - CNPS. Documentos, 132).

FERREIRA, D. F. Sisvar: A computer statistical analysis system. Ciência e Agrotecnologia, v. 35, n. $6, \quad$ p. $1038-1042,2011$. http://dx.doi.org/10.1590/S141370542011000600001 . 
FREIRE, A. L. O.; SARAIVA, V. P.; MIRANDA, J. R. P.; BRUNO, G. B. Crescimento, acúmulo de íons e produção de tomateiro irrigado com água salina. Semina: Ciências Agrárias, v. 31, Suplemento 1, p. 1133-1144, 2010. http://dx.doi.org/10.5433/1679-

0359.2010v31n4Sup1p1133.

GUALBERTO, A. F.; FERRARI, G. M.; ABREU, K. M. P.; PRETO, B. L.; FERRARI, J. L. Características, propriedades e potencialidades da moringa (Moringa oleifera Lam.): Aspectos agroecológicos. Revista Verde de Agroecologia e Desenvolvimento Sustentável, v. 9, n. 5, p. 19-25, 2014.

LEITE, R. S.; TANAN, T. T.; NASCIMENTO, M. N.; OLIVEIRA, L. M.; ABREU, P. A. S. Hydroponic cultivation of Physalis angulata L.: growth and production under nitrogen doses. Pesquisa Agropecuária Tropical, v. 47, n. 2, p. 145-151, 2017. http://dx.doi.org/10.1590/1983$40632016 v 4744652$.

LIMA, G. S.; NOBRE, R. G.; GHEYI, H. R.; SOARES, L. A. A.; LOURENÇO, G. S.; SILVA, S. S. Aspectos de crescimento e produção da mamoneira irrigada com águas salinas e adubação nitrogenada. Revista Brasileira de Engenharia Agrícola e Ambiental, v. 6, n. 8, p. 615-622, 2014. http://dx.doi.org/10.1590/S1415-

43662014000600008.

MENEZES JÚNIOR, J. C; SANTOS, R. V; SOBRINHO, W. N; SOUTO, J. S. Emprego de corretivos químicos, fontes e doses de fósforo em solo degradado por sais na produção do milheto (Pennisetum glaucum L.). Revista Acadêmica: Ciências Agrárias e Ambientais, v. 8, n. 1, p.3945 , 2010. http://dx.doi.org/10.7213/cienciaanimal.v8i1.1040 9

MUNNS, R.; TESTER, M. Mechanisms of salinity tolerance. Annual Review of Plant Biology, v. 59, n. $1, \quad$ p. $\quad 651-681, \quad 2008$. http://dx.doi.org/10.1146/annurev.arplant.59.0326 07.092911.

NOBRE, R. G.; GHEYI, H. R.; CORREIA, K. G.; SOARES, F. A. L.; ANDRADE, L. O.
Crescimento e floração do girassol sob estresse salino e adubação nitrogenada. Revista Ciência Agronômica, v. 41, n. 3, p. 358-365, 2010.

NOBRE, R. G.; LIMA, G. S.; GHEYI, H. R.; LOURENÇO, G. S.; SOARES, L. A. A. Emergência, crescimento e produção da mamoneira sob estresse salino e adubação nitrogenada. Revista Ciência Agronômica, v. 44, n. 1, p. 76-85, 2013.

OLIVEIRA, F. A.; GUEDES, R. A. A.; GOMES, L. P.; BEZERRA, F. M. S.; LIMA, L. A.; OLIVEIRA, M. K. T. Interação entre salinidade e bioestimulante no crescimento inicial de pinhãomanso. Revista Brasileira de Engenharia Agrícola e Ambiental, v. 19, n. 3, p. 204-210, $2015 . \quad$ http://dx.doi.org/10.1590/18071929/agriambi.v19n3p204-210.

OLIVEIRA, F. A.; OLIVEIRA, M. K. T.; SILVA, R. C. P.; SILVA, O. M. P.; MAIA, P. M. E.; CÂNDIDO W. S. Crescimento de mudas de moringa em função da salinidade da água e da posição das sementes nos frutos. Revista Árvore, v. 37, n. 1, p. 79-87, 2013. http://dx.doi.org/10.1590/S010067622013000100009.

OLIVEIRA, F. A; MEDEIROS, J. F; ALVES, R. C; LINHARES, P. S. F; MEDEIROS, A. M. A; OLIVEIRA, M. K. T. Interação entre salinidade da água de irrigação e adubação nitrogenada na cultura da berinjela. Revista Brasileira de Engenharia Agrícola e Ambiental, v. 18, n. 5, p. 480-486, 2014. http://dx.doi.org/10.1590/S141543662014000500003.

PEDROTTI, A.; CHAGAS, R. M.; RAMOS, V. C.; PRATA, A. P. N.; LUCAS, A. A. T.; SANTOS, P. B. Causas e consequências do processo de salinização dos solos. Revista Eletrônica em Gestão, Educação e Tecnologia Ambiental, v. 19, n. 2, p. 1308-1324, 2015.

SÁ, F. V. S.; ARAUJO, J. L.; NOVAES, M. C.; SILVA, A. P.; PEREIRA, F. H. F.; LOPES. K. P. Crescimento inicial de arbóreas nativas em solo salino-sódico do nordeste brasileiro tratado com corretivos. Revista Ceres, v. 60, n. 3, p. 388-396, 
2013. 737X2013000300012.

http://dx.doi.org/10.1590/S0034-

SÁ, F. V. S.; GUEYI, H. R.; LIMA, G. S.; PAIVA, E. P.; FERNANDES, P. D.; MOREIRA, R. C. L.; SILVA, L. A.; FERREIRA NETO, M. Water relations and gas exchanges of West Indian Cherry under salt stress and nitrogen and phosphorus doses. Journal of Agricultural Science, v. 9, n. 10, p. 168-177, 2017. http://dx.doi.org/10.5539/jas.v9n10p168.

SÁ, F. V. S.; MESQUITA, E. F.; MELO, U. A.; E. P.; BERTINO, A. M. P.; MOREIRA, R. C. L. Crescimento e biomassa em plantas de sorgo sacarino irrigados com água salina sob adubação fosfatada. Revista Brasileira de Agricultura Irrigada, v. 12, n. 2, p. 2561-2569, 2018. http://dx.doi.org/10.7127/rbai.v12n200826.
SANTOS, H. G. dos, JACOMINE, P. K. T.; ANJOS, L. H. C.; OLIVEIRA, V. A.; OLIVEIRA, J. B.; COELHO, M. R.; LUMBRERAS, J. F.; CUNHA, T. J. F. Sistema Brasileiro de Classificação de Solos. 3 ed. Brasília, DF: Embrapa Solos, 2013. 353 p.

SILVA, O. M. P.; OLIVEIRA, F. A.; MAIA, P. M. E.; SILVA, R. C. P.; CANDIDO, W. S. Crescimento de mudas de moringa (Moringa oleífera Lam.) submetidas ao estresse salino. Revista Verde de Agroecologia e Desenvolvimento Sustentável, v. 6, n. 1, p. 141147, 2011.

TAIZ, L.; ZEIGER, E.; MØLLER, I. M.; MURPHY, A. Fisiologia e desenvolvimento Vegetal. 6. ed. Porto Alegre: Artmed, 2017. 858p. 